\title{
Factors Affecting the End-of Life Care Competency of Tertiary Hospital Nurses
}

\author{
Da-In Jeong, R.N. and Young Eun, R.N., Ph.D.* \\ Department of Nursing, Gyeongsang National University Hospital, \\ ${ }^{*}$ College of Nursing, Institute of Health Sciences, Gyeongsang National University, Jinju, Korea
}

Purpose: The purpose of this study was to investigate the levels of end-of-life care competency; knowledge, attitudes, and experiences regarding advance directives; perceptions of good death; and end-of-life care obstacles and supportive behaviors among tertiary care nurses. Methods: The participants were 150 nurses at a tertiary hospital in Jinju, Korea. The data collected using a questionnaire were analyzed using descriptive statistics, the t-test, analysis of variance, Pearson correlation coefficients, and stepwise multiple regression in SPSS for Windows version 24.0. Results: The mean $( \pm S D)$ score of end-of-life care competency was $3.63( \pm 0.53)$ on a $5-$ point scale. A significant difference in end-of-life care competency was found according to whether nurses had experienced the death of a family member or acquaintance $(\mathrm{P}=0.029)$. According to stepwise multiple regression analysis, the factors affecting end-of-life care competency were the frequency of end-of-life care supportive behaviors $(\beta=0.38, \mathrm{P}<0.001)$, experience with advance directives $(\beta=0.29, \mathrm{P}<0.001)$, and marriage $(\beta=0.15, \mathrm{P}=0.039)$. This model had an explanatory power of $27.9 \%(\mathrm{~F}=18.87, \mathrm{P}$ $<0.001$ ). Conclusion: In order to improve nurses' end-of-life care competency, it is important to strengthen end-of-life care supportive behaviors by exposing nurses to those behaviors and providing frequent experience with advance directives.

Key Words: Nurses, Terminal care, Advance directives, Death
Received March 29, 2020

Revised July 28, 2020

Accepted August 7, 2020

Correspondence to

Young Eun

ORCID:

https://orcid.org/0000-0002-3497-8192

E-mail:yyoeun@gnu.ac.kr

\section{INTRODUCTION}

\section{Background}

In South Korea, $74.9 \%$ of deaths occurred at a hospital in 2016, which increased slightly to $76.2 \%$ in 2017 18 [1]. However, the majority of patients face death alone in intensive care units, relying on machines, in pain, and separated from their family. They experience death devoid of any meaning, as their autonomy is neglected [2]. This highlights the need for more efficient and professional end-of-life care for patients who are near death and their family members [3]. In recent years, increasing interest has emerged in questions such as what kind of death is a human death, what is a good death, and what is a dignified death [4].

Nurses spend many hours close to patients and family members and provide care while connecting and interacting with the full range of their being, including physical, emotional, and spiritual aspects [3]. In the clinical setting, nurses act as advocates for patients who protect patients' autonomy and rights and perform the important role of helping patients make decisions about death [5]. Therefore, nurses need to be able to provide holistic end-of-life care so that patients can meet death in a dignified manner, and in order to perform such 
nursing duties, nurses need the ability to apply appropriate techniques, knowledge, and attitudes for professional nursing practice [6].

End-of-life care competency refers to the nursing capacity required to provide care to end-of-life patients [7]. Montagnini et al. [8] categorized end-of-life care competencies into symptom management; patients' and family members' decision-making; knowledge regarding spiritual caregiving, attitudes about decision-making on end-of-life treatment, communication among medical staff, patients, and family members; continuity of care; and behavioral competency regarding emotional support for nurses.

The literature on end-of-life care competency among nurses includes a Delphi study that aimed to outline the necessary competencies for end-of-life care among healthcare workers [9]; a study on end-of-life care competency and facilitators and barriers to end-of-life care among intensive care unit nurses [10]; a study on end-of-life care competency and stress associated with end-of-life care among nurses in care facilities [11]; a study on the effects of attitudes, experience, and knowledge on advance directives and the influence of perceptions of a good death on end-of-life care competency and the performance of end-of-life care among nurses at general hospitals [12]; and a study on end-of-life care competency and the frequency of end-of-life care among nurses at tertiary hospitals [13]. Since the Act on Hospice and Palliative Care and Decisions on Life-Sustaining Treatment for Patients at the End of Life (hereinafter referred to as the Act on Decisions on Life-Sustaining Treatment) was revised in 2018, advance directives are being documented regarding end-of-life care in actual clinical settings, and at the same time, there is an increasing recognition of the importance of a good death and a demand for high quality end-of-life care from nurses; therefore, research investigating the end-of-life care competency of nurses in South Korea is needed.

An advance directive is a policy that aims to protect the dignity and value of human life by guaranteeing the best interest of patients in the dying process and respecting their selfdetermination [14]. Patients' value systems have a substantial influence on the completion of advance directives, but the systematic adaptation of advanced directives and the proportion of advance directives filed are to a certain extent dependent on hospital policies and the efforts made by medical staff. Nurses' experience with completing advance directives will help patients and family members complete advance directives appropriately [15]. Moreover, if nurses acquire the knowledge to provide sufficient and accurate information regarding advance directives to patients and family members and if nurses adopt a positive attitude that will help them perform the roles of facilitator, supporter, and educator based on that knowledge, their clinical performance and end-of-life care competency will both be affected [16].

Nurses' perceptions of a good death can facilitate accurate perceptions and positive attitudes regarding hospice and palliative care and the discontinuation of meaningless life-sustaining treatments to patients and family members [17], help patients and family members establish a recognition of good death, enhance the end-of-life care competency of nurses [12], and help patients to maintain their dignity as human beings and overcome their fear of death to meet death in a peaceful manner [18].

However, nurses feel considerable pressure about performing end-of-life care and are often not able to demonstrate their competency due to various factors in the work environment, such as the decision-making required for end-of-life care, stress, the acquisition of new knowledge and skills, and work burden; therefore, it is important to enhance the end-of-life care competency of nurses [10] based on an understanding of the barriers and facilitators [19].

Barriers to end-of-life care refer to conditions that hinder nurses from performing end-of-life care [20], which include unrealistic expectations regarding treatment effects and prognoses from patients and family members, the fact that most patients are unable to participate in the treatment process, a lack of communication skills about caring for end-of-life patients, and a lack of time among medical staff to provide adequate end-of-life care [20].

Supportive behaviors for end-of-life care are conditions that facilitate end-of-life care [20]. Examples include managing patients' pain and discomfort, respecting patients' wishes regarding end-of-life care, discontinuing active interventions early when there is no possibility of recovery, communicating effectively with medical staff, managing visiting times in a flexible manner, and providing a quiet environment [21]. 
Therefore, this study investigated nurses' end-of-life care competency; knowledge, attitudes, and experiences regarding advance directives; perceptions of good death; barriers to end-of-life care; and supportive behaviors, with the goal of enhancing their end-of-life care competency and improving the quality of end-of-life care of nurses. It also examined correlations among these factors to provide foundational materials for the development of strategies and educational programs that can enhance end-of-life care competency, which is necessary to provide high quality end-of-life care.

\section{Purpose}

The aim of this study was to obtain insights into end-of-life care competency; knowledge, attitudes, and experiences regarding advance directives; perceptions of good death; barriers to end-of-life care; and supportive behaviors among nurses at tertiary hospitals and to examine factors that influence endof-life care competency.

\section{METHODS}

\section{Study participants}

The participants of this study were nurses working at a tertiary hospital in J city, South Gyeongsang Province, South Korea who had more than 6 months of clinical experience and who provided written informed consent after indicating that they understood the aim of the study.

The number of participants was calculated using G*Power version 3.1.9.4, and the sample size needed for an effect size of 0.15 [12], a significance level of 0.05 , a power of 0.90 , and six predictors (total number of predictors: 13) was 123. Considering the expected dropout rate, 150 surveys were distributed and all 150 were collected. There were no surveys with missing data; therefore, all 150 surveys were used for the final data analysis.

\section{Research tools}

All measurement tools were used after receiving permission from the authors.

\section{1) End-of-life care competency}

End-of-life care competency refers to the skills, knowledge, experience, attributes, and behaviors required to perform endof-life care [7] and the end-of-life care competency tool developed by Montagnini et al. [8] and translated by, was used. The tool consists of 28 items with 5-point Likert scale ranging from "not applicable" (0) and "not at all" (1) to "always" (5), and higher scores indicate higher end-of-life care competency. Regarding the reliability of the tool, Cronbach's $\alpha$ was 0.92 in the study of Montagnini et al. [8], 0.89 in the study of Lee [10], and 0.91 in the current study.

\section{2) Knowledge of advance directives}

Knowledge of advance directives refers to the extent of one's overall understanding of the completion of advance directives [22]. To measure knowledge about advance directives, a tool developed by Hong and Kim [22] and revised and supplemented by Seo [23] following the revision of the Act on Decisions on Life-Sustaining Treatment in 2018 was used. The tool consists of 12 items, and a higher total score (sum of each item score) corresponds to more knowledge about advance directives. The reliability of the scale was $\mathrm{KR}_{20}=0.85$ in Hong and Kim [22], Cronbach's $\alpha=0.87$ in Seo [23], and $\mathrm{KR}_{20}=0.60$ in the current study.

\section{3) Attitudes toward and experiences with advance directives}

Attitudes toward advance directives refer to the subjective judgement of perceptions, emotions, and evaluation regarding advance directives [24], while experience with advance directives refers to real-life participation and experiences of the process of completing advance directives [24].

In order to measure attitudes towards and experiences with advance directives, the attitude and experiences sections from the Knowledge, Attitudinal, Experiential Survey on Advance Directives developed by Jezewski et al. [25] and translated and revised by Kim and Kim [24] was used. The attitudes section comprises nine items, after the elimination of one item with low reliability, which are scored on a 4-point Likert scale from "almost never" (1), "barely" (2), and "mostly" (3) to "always" (4), with higher total scores (sum of each item score) indicating more positive attitudes towards advance directives. The reliability of the tool measured with Cronbach's $\alpha$ was 
somewhat low, with values of 0.57 reported by Jezewski et al. [25], 0.62 by Kim and Kim [24], and 0.58 in the current study. Although the degree of matching was not high, since attitudes are positive or negative evaluations of certain behaviors or situations [24], the tool was used in order to measure subjective opinions on advance directives.

The experience section contains seven items, for which 1 point is given when a respondent reports having a certain $\mathrm{ex}^{-}$ perience ("yes") and a score of 0 is given for a response of "no". Higher total scores indicate more experience with advance directives. Regarding reliability, Cronbach's $\alpha$ was 0.58 in the study of Jezewski et al. [25] and 0.70 in the study of Kim and Kim [24], while $\mathrm{KR}_{20}$ was 0.79 in this study.

\section{4) Perceptions of a good death}

Perceptions of good death refer to the concept or process of being treated as a holistic human being whose values and beliefs are respected in the process of death [26].

Perceptions of good death were measured using the tool developed by Schwartz et al. [26] and translated by Jeong [27]. The tool contains 17 items distributed across three subdomains (familiarity, sense of control, and clinical symptoms), and uses a 4-point Likert scale from "not important at all" (1) to "very important" (4). A higher total score (sum of each item score), indicates higher perceptions of good death. The reliability measured with Cronbach's $\alpha$ was 0.87 in the study of Schwartz et al. [26], 0.82 in Jeong's study [27], and 0.80 in the current study.

\section{5) End-of-life care obstacles and supportive behaviors}

Obstacles to end-of-life care are perspectives or behaviors that prevent sufficient function in providing end-of-life care, and supportive behaviors are perspectives or behaviors that facilitate the best function of end-of-life care [20].

The measurement tool for end-of-life care obstacles and supportive behaviors was the tool developed for intensive care unit nurses by Beckstrand and Kirchhoff [21], which was translated, revised, and supplemented by Lee [10]. Both obstacles and supportive behaviors had three sub-domains ( $\mathrm{pa}^{-}$ tient and family, medical staff, and hospital and department). The tool for end-of-life care obstacles contains 29 items that measure intensity and frequency with a 6-point Likert scale.
Intensity is measured from "never an obstacle" (0) to "an extreme obstacle" (5), with higher scores indicating a greater intensity of the obstacle. Frequency is measured from "never occurs" (0) to "always occurs" (5), with higher score indicating a more frequently experienced obstacle. The Perceived Intensity Score (PIS) for barriers is calculated by multiplying the intensity score and the frequency score of each item, with a higher score indicating that respondents perceive the obstacle as having a higher intensity. The reliability of the tool measured by Cronbach's $\alpha$ was 0.89 for both intensity and frequency in the study by Beckstrand and Kirchhoff [21]; 0.82 for intensity, 0.84 for frequency, and 0.86 for the PIS in Lee's study [10]; and 0.90 for intensity, 0.91 for frequency, and 0.91 for the PIS in the current study.

The tool for supportive behaviors of end-of-life care consists of 24 items that measure intensity and frequency with a 6-point Likert scale. Intensity is measured from "never a supportive behavior" (0) to "an extremely supportive behavior" (5), with higher score indicating that a behavior is considered more supportive. Frequency is measured from "never occurs" (0) to "always occurs" (5), with a higher score indicating a more frequently experienced supportive behavior. The Perceived Supportive Behavior Score (PSBS) is calculated by multiplying the intensity score and the frequency score of each item, with a higher score indicating that respondents perceive the supportive behavior as having a higher intensity. The reliability of the tool measured by Cronbach's $\alpha$ was 0.86 for intensity and 0.81 for frequency in the study of Beckstrand and Kirchhoff [21]; 0.91 for intensity, 0.84 for frequency, and 0.85 for PSBS in Lee's study [10]; and 0.91 for intensity, 0.90 for frequency, and 0.92 for PSBS in the current study.

\section{Data collection}

This study was approved by the G University Hospital Clinical Research IRB (2019-05-017-001) and the Department of Nursing, and data was collected at the department from September 1 to 10, 2019 with clinical nurses as participants. The researcher visited the department to explain the aim and purpose of the study and received written approval for data collection from the department head. The aim and purpose of the study were also explained to the head nurses of each ward, and the participants completed the survey after provid- 
ing written consent to participate in the study voluntarily upon reading the consent form that contained an explanation on the aim of the study, duration of the study, and protection of data. Participants were notified that they could discontinue their participation at any point during the survey, and those who completed the survey received a small token of appreciation. Personal information on collected surveys was carefully kept confidential and only used for research purposes in consideration of ethical protections for the participants.
1) The general characteristics and the descriptive statistics of research variables were analyzed in terms of frequency, percentages, and mean and standard deviations.

2) Differences in end-of-life care competency by participants' general characteristics were analyzed with the independent $t$-test and one-way analysis of variance.

3) Stepwise multiple regression analysis was performed to identify the factors that influenced end-of-life care competency of participants.

\section{Data analysis}

The collected data were analyzed using SPSS for Windows version 24.0 (IBM Corp., Armonk, NY, USA).

Table 1. General Characteristics of Participants ( $N=150)$.

\begin{tabular}{|c|c|c|c|c|}
\hline Variable & Categories & $n$ & $\%$ & Mean $\pm S D$ \\
\hline \multirow[t]{4}{*}{ Age (yr) } & $\geq 25$ & 24 & 16.0 & $28.3 \pm 4.51$ \\
\hline & $25 \sim 29$ & 81 & 54.0 & \\
\hline & $30 \sim 34$ & 31 & 20.7 & \\
\hline & $35 \leq$ & 14 & 9.3 & \\
\hline \multirow[t]{2}{*}{ Sex } & Female & 144 & 96.0 & \\
\hline & Male & 6 & 4.0 & \\
\hline \multirow[t]{2}{*}{ Marital status } & Unmarried & 106 & 70.7 & \\
\hline & Married & 44 & 29.3 & \\
\hline \multirow[t]{3}{*}{ Education level } & Associate's degree & 35 & 23.3 & \\
\hline & Bachelor's degree & 94 & 62.7 & \\
\hline & Graduate degree & 21 & 14.0 & \\
\hline \multirow[t]{2}{*}{ Religion } & Yes & 54 & 36.0 & \\
\hline & No & 96 & 64.0 & \\
\hline \multirow[t]{4}{*}{ Current work department } & Intensive care unit & 69 & 46.0 & \\
\hline & Internal medicine unit & 41 & 27.3 & \\
\hline & Surgery unit & 20 & 13.3 & \\
\hline & Emergency department & 20 & 13.3 & \\
\hline \multirow[t]{4}{*}{ Clinical career (yr) } & $>3$ & 37 & 24.7 & $5.68 \pm 4.19$ \\
\hline & $3 \sim 5$ & 51 & 34.0 & \\
\hline & $5 \sim 10$ & 37 & 24.7 & \\
\hline & $10 \leq$ & 25 & 16.7 & \\
\hline \multirow[t]{5}{*}{ Experience at current work department (yr) } & $>1$ & 26 & 17.3 & $3.51 \pm 3.02$ \\
\hline & $1 \sim 3$ & 43 & 28.7 & \\
\hline & $3 \sim 5$ & 54 & 36.0 & \\
\hline & $5 \sim 10$ & 21 & 14.0 & \\
\hline & $10 \leq$ & 6 & 4.0 & \\
\hline \multirow[t]{2}{*}{ Experience of end-of-life care } & Yes & 140 & 93.3 & \\
\hline & No & 10 & 56.7 & \\
\hline \multirow[t]{2}{*}{ Experience of end-of-life care education } & Yes & 42 & 28.0 & \\
\hline & No & 108 & 72.0 & \\
\hline \multirow{2}{*}{$\begin{array}{l}\text { Experience of the death of a family member or } \\
\text { acquaintance }\end{array}$} & Yes & 84 & 56.0 & \\
\hline & No & 66 & 44.0 & \\
\hline
\end{tabular}




\section{RESULTS}

\section{General characteristics of participants}

The average age of the study participants was 28.3 years, and $54 \%(n=81)$ were from 25 to 29 years of age. The overwhelming majority $(96 \% ; n=144)$ were female, while $4 \%(n=6)$ were male. Furthermore, $70.7 \%(n=106)$ were not married, while $29.3 \%(n=44)$ were married. Most frequently, participants had graduated from university $(62.7 \% ; n=94)$ and were not religious $(64 \% ; n=96)$. Their current work department was the intensive care unit for $46 \%(n=69)$, the internal medicine unit for $27.3 \%(n=41)$, the surgery unit for $13.3 \%(n=20)$, and the emergency department for $13.3 \%(n=20)$. The participants had, on average, 5.7 years of clinical experience, with $34 \%$ $(n=51)$ having 3 to 5 years of experience and $24.7 \% \quad(n=37)$ each having less than 3 years and 5 to 10 years of experience. Their length of work in their current department was on average 3.5 years, with $36 \%(n=54)$ from 3 to 5 years and $28.7 \%$ $(n=43)$ from 1 to 3 years. Although 93.3\% $(n=140)$ had experienced end-of-life care, $72 \%(n=108)$ reported never having receiving education on end-of-life care and only $28 \%(n=42)$ reported that they had. The type of education received included refreshers and online classes. Approximately half (55.3\%; $n=83$ ) of the participants had experienced the death of a family member or acquaintance (Table 1).

\section{Levels of end-of-life care competency; knowledge, attitudes, and experiences regarding advance directives; perceptions of good death; and end-of-life care obstacles and supportive behaviors}

The mean score for the end-of-life care competency of the participants was $3.63 \pm 0.53$ out of 5 . The mean score for knowledge on advance directives was $10.01 \pm 1.79$ out of 12 , with the average percentage of correct answers being $83.4 \%$. The mean score for attitudes towards advance directives was $2.69 \pm 0.78$ out of 4 . The mean score for experiences with advance directives was $1.88 \pm 1.85$ out of 7 . The mean score for perceptions of a good death was $3.02 \pm 0.35$ out of 4 .

The mean frequency score for end-of-life care obstacles was $2.81 \pm 0.56$ out of 5 , and the mean scores by sub-domains were $3.26 \pm 0.58$ for patient/family, $2.79 \pm 0.66$ for medical staff, and $2.35 \pm 0.87$ for hospital/department.

The mean frequency score for end-of-life care supportive behaviors was $2.71 \pm 0.62$ out of 5 , and the mean scores by sub-domains were $3.04 \pm 0.82$ for patient/family, $2.76 \pm$ 0.70 for medical staff, and $2.48 \pm 0.77$ for hospital/department (Table 2).

\section{Differences in the levels of end-of-life care competency by general characteristics}

Participants who had experienced the death of a family

Table 2. Levels of End-of-Life Care Competency; Knowledge, Attitudes, and Experience Regarding Advance Directives; Perceptions of a Good Death; and End-ofLife Care Obstacles and Supportive Behaviors ( $N=150)$.

\begin{tabular}{|c|c|c|c|c|}
\hline Variable & Sub-domain & Mean $\pm S D$ & Min & Max \\
\hline End-of-life care competency & & $3.63 \pm 0.53$ & 2.68 & 4.33 \\
\hline Knowledge of advance directives & & $10.01 \pm 1.79$ & & \\
\hline Attitudes toward advance directives & & $2.69 \pm 0.78$ & 2.19 & 3.46 \\
\hline Experience with advance directives & & $1.88 \pm 1.85$ & & \\
\hline Perceptions of good death & & $3.02 \pm 0.35$ & 1.93 & 3.55 \\
\hline \multirow[t]{4}{*}{ Frequency of end-of-life care obstacles } & Patient/family & $3.26 \pm 0.58$ & 2.69 & 3.80 \\
\hline & Health provider & $2.79 \pm 0.66$ & 1.68 & 3.46 \\
\hline & Hospital/department & $2.35 \pm 0.87$ & 1.77 & 2.96 \\
\hline & Total & $2.81 \pm 0.56$ & 1.68 & 3.80 \\
\hline \multirow[t]{4}{*}{ Frequency of end-of-life care supportive behaviors } & Patient/family & $3.04 \pm 0.28$ & 2.56 & 3.37 \\
\hline & Health provider & $2.76 \pm 0.70$ & 2.51 & 3.17 \\
\hline & Hospital/department & $2.48 \pm 0.77$ & 1.87 & 3.11 \\
\hline & Total & $2.71 \pm 0.62$ & 1.87 & 3.37 \\
\hline
\end{tabular}


member or acquaintance had statistically significantly higher end-of-life care competency than those who did not have such an experience (Table 3).

\section{Factors that influenced levels of end-of-life care competency among participants}

In order to examine the factors that influenced end-of-life care competency, general characteristics that demonstrated a significant difference (marital status, experience of end-of-life care, and having experienced the death of a family member or acquaintance); knowledge, attitudes, and experiences regarding advance directives; perceptions of a good death; intensity, frequency, and PIS of end-of-life care obstacles; and intensity, frequency, and PSBS of end-of-life care supportive behaviors were analyzed as independent variables in simple regression analyses (Table 4).

Multiple regression analysis was conducted with significant variables from the simple regression analyses (marital status as a dummy variable, experience with advance directives, and frequency of end-of-life care supportive behaviors). When autocorrelation of variables was checked, the Durbin-Watson indicator was 1.634, close to the standard score of 2 that indicates no autocorrelation. The variance inflation factor was less than 10 (1.105 5.777), and the tolerance was 0.472 0.891, which was in the acceptable range from 0.1 to 1.0. Therefore, no multicollinearity was found. The regression model met the criteria of the regression function and demonstrated a good fit. Marital status ( $\beta=0.15, P=0.039)$, experience with advance

Table 3. Differences in End-of-Life Care Competency According to General Characteristics ( $N=150$ ).

\begin{tabular}{|c|c|c|c|c|c|}
\hline \multirow{2}{*}{$\begin{array}{ll} & \text { Variable } \\
\text { Age }(y r) & \end{array}$} & \multirow{2}{*}{$\begin{aligned} \quad \text { Categories } \\
\geq 25\end{aligned}$} & \multirow{2}{*}{$\begin{array}{l}n \\
24\end{array}$} & \multicolumn{2}{|c|}{ Total mean $( \pm \mathrm{SD})$} & \multirow[t]{2}{*}{$\mathrm{P}$} \\
\hline & & & 3.74 & \pm 0.46 & \\
\hline & $25 \sim 29$ & 81 & 3.54 & \pm 0.54 & 0.157 \\
\hline & $30 \sim 34$ & 31 & 3.67 & \pm 0.56 & \\
\hline & $35 \leq$ & 14 & 3.82 & \pm 0.50 & \\
\hline \multirow[t]{2}{*}{ Sex } & Female & 144 & 3.36 & \pm 0.74 & 0.212 \\
\hline & Male & 6 & 3.64 & \pm 0.52 & \\
\hline \multirow[t]{2}{*}{ Marital status } & Unmarried & 106 & 3.57 & \pm 0.53 & 0.055 \\
\hline & Married & 44 & 3.76 & \pm 0.51 & \\
\hline \multirow[t]{3}{*}{ Education level } & Associate's degree & 35 & 3.70 & \pm 0.50 & 0.340 \\
\hline & Bachelor's degree & 94 & 3.58 & \pm 0.54 & \\
\hline & Graduate degree & 21 & 3.73 & \pm 0.55 & \\
\hline \multirow[t]{2}{*}{ Religion } & Yes & 54 & 3.62 & \pm 0.54 & \\
\hline & No & 96 & 3.63 & \pm 0.53 & 0.866 \\
\hline \multirow[t]{4}{*}{ Current work department } & Intensive care unit & 69 & 3.72 & \pm 0.49 & \\
\hline & Internal medicine unit & 41 & 3.56 & \pm 0.74 & 0.535 \\
\hline & Surgical unit & 20 & 3.58 & \pm 0.50 & \\
\hline & Emergency department & 20 & 3.67 & \pm 0.49 & \\
\hline \multirow[t]{4}{*}{ Clinical career (yr) } & $>3$ & 37 & 3.69 & \pm 0.51 & \\
\hline & $3 \sim 5$ & 51 & 3.53 & \pm 0.54 & 0.367 \\
\hline & $5 \sim 10$ & 37 & 3.64 & \pm 0.46 & \\
\hline & $10 \leq$ & 25 & 3.72 & \pm 0.63 & \\
\hline \multirow[t]{4}{*}{ Experience at current work department (yr) } & $>1$ & 26 & 3.62 & \pm 0.40 & \\
\hline & $1 \sim 3$ & 43 & 3.57 & \pm 0.59 & 0.840 \\
\hline & $3 \sim 5$ & 54 & 3.65 & \pm 0.56 & \\
\hline & $5 \sim 10$ & 27 & 3.68 & \pm 0.49 & \\
\hline \multirow[t]{2}{*}{ Experience of end-of-life care } & Yes & 140 & 3.65 & \pm 0.52 & 0.058 \\
\hline & No & 10 & 3.32 & \pm 0.52 & \\
\hline \multirow[t]{2}{*}{ Experience of end-of-life care education } & Yes & 42 & 3.75 & \pm 0.49 & 0.082 \\
\hline & No & 108 & 3.58 & \pm 0.54 & \\
\hline \multirow{2}{*}{$\begin{array}{l}\text { Experience of the death of a family member or } \\
\text { acquaintance }\end{array}$} & Yes & 84 & 3.71 & \pm 0.50 & 0.029 \\
\hline & No & 66 & 3.52 & \pm 0.55 & \\
\hline
\end{tabular}


Table 4. Simple Regression on End-of-Life Care Competency.

\begin{tabular}{|c|c|c|c|c|c|c|}
\hline & Variables & $B$ & SE & $\beta$ & $\mathrm{t}$ & $P$ \\
\hline Constant & & 1.208 & 0.844 & - & 1.432 & 0.154 \\
\hline \multirow[t]{3}{*}{ General characteristics } & Marriage* & 0.134 & 0.085 & 0.116 & 1.582 & 0.043 \\
\hline & Experience of end-of-life care ${ }^{\dagger}$ & 0.036 & 0.161 & 0.017 & 0.222 & 0.825 \\
\hline & $\begin{array}{l}\text { Experience of the death of a family } \\
\text { member or acquaintance }{ }^{\ddagger}\end{array}$ & 0.098 & 0.079 & 0.093 & 1.253 & 0.212 \\
\hline \multirow[t]{11}{*}{ Independent variables } & Knowledge of advance directives & 0.018 & 0.024 & 0.061 & 0.761 & 0.448 \\
\hline & Attitudes toward advance directives & 0.140 & 0.137 & 0.075 & 1.018 & 0.311 \\
\hline & Experience with advance directives & 0.081 & 0.021 & 0.282 & 3.840 & $<0.001$ \\
\hline & Perceptions of a good death & 0.097 & 0.113 & 0.064 & 0.860 & 0.391 \\
\hline & Intensity of end-of-life care obstacles & -0.179 & 0.166 & -0.178 & -1.078 & 0.283 \\
\hline & Frequency of end-of-life care obstacles & -0.124 & 0.195 & -0.134 & -0.634 & 0.526 \\
\hline & Perceived intensity score for barriers, PIS & 0.015 & 0.055 & 0.084 & 0.278 & 0.782 \\
\hline & $\begin{array}{l}\text { Intensity of end-of-life care supportive } \\
\text { behaviors }\end{array}$ & 0.344 & 0.168 & 0.354 & 2.043 & 0.083 \\
\hline & $\begin{array}{l}\text { Frequency of end-of-life care supportive } \\
\text { behaviors }\end{array}$ & 0.654 & 0.280 & 0.763 & 2.335 & 0.021 \\
\hline & Perceived supportive behavior score, PSBS & -0.094 & 0.070 & -0.535 & -1.356 & 0.177 \\
\hline & \multicolumn{6}{|c|}{ Durbin-Watson=1.633, F=5.59, $P<0.001, R^{2}=0.348, A d j-R^{2}=0.286$} \\
\hline
\end{tabular}

*Dummy variable (unmarried:0, married:1), ${ }^{\dagger}$ dummy variable (no:0, yes:1), ${ }^{\dagger}$ dummy variable (no:0, yes:1).

Table 5. Factors Affecting End-of-Life Care Competency.

\begin{tabular}{lccccc}
\hline \multicolumn{1}{c}{ Variables } & $\mathrm{B}$ & $\mathrm{SE}$ & $\beta$ & $\mathrm{t}$ & $\mathrm{P}$ \\
\hline Constant & 2.546 & 0.169 & & 15.03 & $<0.001$ \\
Frequency of end-of-life care supportive behaviors & 0.323 & 0.061 & 0.38 & 5.31 & $<0.001$ \\
Experience withadvance directives & 0.082 & 0.020 & 0.29 & 4.04 & $<0.001$ \\
Marriage* & 0.170 & 0.081 & 0.15 & 2.09 & 0.039 \\
& Durbin-Watson=1.634, $\mathrm{F}=18.87, \mathrm{P}<0.001, \mathrm{R}^{2}=0.279, \mathrm{Adj}^{-R^{2}=0.265}$ & & \\
\hline
\end{tabular}

*Dummy variable (unmarried:0, married:1).

directives $(\beta=0.29, \mathrm{P}<0.001)$, and frequency of end-of-life care supportive behaviors $(\beta=0.38, \mathrm{P}<0.001)$ were found to influence the end-of-life care competency of participants. The regression model explained 27.9\% of the variance and was statistically significant $(\mathrm{F}=18.87, \mathrm{P}<0.001)$ (Table 5).

\section{DISCUSSION}

This study examined nurses' end-of-life care competency; knowledge, attitudes, and experiences regarding advance directives; perceptions of a good death; and end-of-life care obstacles and supportive behaviors, and investigated factors associated with end-of-life care competency. In this study, the mean score for end-of-life care competency among participants was $3.63 \pm 0.53$ out of 5 . This mean score is lower than that found by Montagnini et al. [8] (3.77); higher than that in Lee's study [10] of nurses at tertiary hospitals (2.99); and similar to those reported by Lee [12] (3.25), Lee [13] (3.24), and Jeong [11] among nurses in nursing facilities (3.54). Among the scores for the sub-domains of end-of-life care competency, the highest score was found for knowledge, followed by behavior and attitudes, which is similar to the trend in previous studies $[8,11,12]$, suggesting that attitudes toward end-of-life care were still relatively immature. In the knowledge competency for end-of-life care, scores were high for pain management and respiratory interventions, consistent with previous studies [10-12]. This finding indicates that endof-life patients frequently require management of pain and symptoms such as dyspnea and loss of appetite [28], so nurses acquired the competencies needed to deal with those require- 
ments. Moreover, consistently with previous studies [10-13], the lowest score was found for spiritual care. Spiritual care was found to be lacking, especially among nurses working in acute care facilities or nursing facilities, which indicates difficulties such as lack of time to perform spiritual care.

Knowledge of advance directives was high, with mean score of 10.01 out of 12 and average percentage correct of $87.3 \%$. Due to the popularity of advance directives and continuing education, participants were highly knowledgeable about patients' right to decide upon and reject care, but knowledge about registration centers and procedures was lacking. Thus, it is necessary to provide continuing education for nurses to acquire knowledge and convey accurate information to patients and family members.

The mean score for attitudes toward advance directives was 2.69 out of 4, indicating moderate attitudes overall, although somewhat positive attitudes were found for certain items (e.g., "Information about current status and treatment alternatives should be provided to patients" and "Even if the patient' $s$ wishes conflict with mine, I need to respect patient's opinions"). However, passive attitudes were found towards other items (e.g., "I should actively help patients complete advance directives" and "Every patient capable of decision-making should complete advance directives"). Therefore, nurses regard the role of providing necessary information from an objective and professional perspective.

The average score for experiences with advance directives was 1.88 out of 7 , which is higher than the average score of 1.44 reported by Kim and Kim [24], but lower than that of 2.95 reported by Um [15] and 2.08 reported by Lee [12]. The most frequent experience was reading about policy or procedures related to advance directives (56.7\%), consistent with the results of Lee [12]. Since more people are exposed to advance directives as time goes by, nurses seem to have taken interest in this phenomenon and to have read about advance directives at minimum. The frequency of experience counseling patients and family members about advance directives was $35.3 \%$ in this study, which is much lower than the proportion of $80.0 \%$ reported by Jezewski et al. [25]. This discrepancy may be due to the fact that death is family-centered in South Korea, and nurses do not intervene as frequently [24]. Therefore, in order for nurses to participate positively and actively in the process of decision-making about and completing advance directives, the role of nurses should be clearly defined, and legal policies that support such a role seem necessary.

In this study, the mean score for perceptions of a good death was 3.02 out of 4 , similar to the scores reported in previous studies that used the same tool among nurses at tertiary hospitals (3.06 in Jeong [27], 2.99 in Cheon [17], and 3.09 in Lee [12]). High scores were found for the following items: "to be with loved ones at the moment of death", "dying peacefully", and "accepting death," similar to the results of Jeong [27]. These results demonstrate that nurses believe that accepting death in a positive manner is a part of life and that dying naturally and peacefully is an important aspect of a good death.

The average of the total frequency score for end-of-life care supportive behaviors was 2.71 , with the highest sub-domain score for the patient/family sub-domain, followed in order by the medical staff and hospital/department sub-domains. The average of the total frequency scores in this study is lower than the average of 4.44 reported by Beckstrand and Kirchhoff [21], who used the same tool among nurses, but slightly higher than that of 2.61 reported by Lee [10]. Among the frequency of end-of-life care supportive behaviors, the frequencies for the items "family members accepting the fact that the patient is dying" and "family members deciding on one main care provider who will communicate on behalf of the rest of the family" in the patient/family sub-domain had high scores. Since the items "many family members other than the main caregiver constantly calling the nurse to ask about the patient status" and "family members not accepting the patient's bad prognosis" were ranked high as obstacles to end-of-life care, it can be inferred that communication between nurses and family members is important in end-of-life care. Therefore, since it is important for medical staff to explain the situation of the patient's death honestly, clearly, and in an easily understandable way to the patient's family in order for them to make the right decisions [29], it is necessary to establish a guideline for designating a main caregiver and creating a network of family and friends for regular communication about the patient's prognosis and treatment [30].

In previous studies $[19,21,30]$, the most supportive behavior was "family members having enough time to spend with the patient after the patient's death", but this item was ranked 
somewhat low in this study, indicating that the care environment in the study setting (tertiary hospitals) lacked space and time. Since environmental changes for a dignified death are important to provide a private and quiet space for patient and family members to feel comfortable at the moment of death and to allow family members to be present at the moment of death [21], steps should be taken to adjust the patient's environment in the department and to provide a suitable space for the support system should be sought. In Lee's study [10], "when the attending nurse is absent after patient death, other nurses taking care of the remaining patient" was the most supportive behavior, but it was ranked relatively low in this study. Departmental-level policies on the distribution of care work seem necessary, and to encourage supportive behaviors of endof-life care, a support system for smooth and effective communication with the patient and the patient's family members should be established at the departmental or the hospital level.

Regarding differences in end-of-life care competency by general characteristics, a statistically significant difference was found according to whether respondents had experienced the death of a family member or acquaintance, with higher competency among such participants. This result is consistent with Jeong [11]. End-of-life care competency was also found to be higher, but at the threshold of statistical significance, in participants who had experience with end-of-life care than in those who did not and in married participants than in unmarried participants. Although no previous studies have reported analogous results, some have reported significant differences by age $[10,13]$ and clinical experience $[10,11]$, which indirectly support these results. As nurses are exposed to more death and obtain more end-of-life care experience, their end-of-life care competency increases.

In order to examine the factors that influence end-of-life care competency, general characteristics that demonstrated significant differences (marital status, experience in end-of-life care, and having experienced the death of a family member or acquaintance); knowledge, attitudes, and experiences regarding advance directives; perceptions of a good death; intensity, frequency, and PIS of end-of-life care obstacles; and intensity, frequency, and PSBS of end-of-life care supportive behaviors were analyzed as independent variables in simple regression analyses. The frequency of end-of-life care supportive be- haviors, experience with advance directives, and marital status were found to influence the end-of-life care competency among participants, and the regression model explained 27.9\% of the variance. In Lee [12], communication with and the level of support from patients who discontinued life-sustaining treatments and their family members, which can be understood as similar to frequency of end-of-life supportive behaviors, were found to influence end-of-life care competency. The finding regarding experience with advance directives influencing end-of-life care competency is consistent with those of Lee [12]. Knowledge about advance directives and perceptions of a good death did not have statistically significant influence on end-of-life care competency in this study, but in Lee' s study [12], which was conducted among nurses at tertiary hospitals, these factors were found to influence end-of-life care competency and explained $34.4 \%$ of the variance, so a further examination of the factors affecting end-of-life care competency is warranted.

In summary, when supportive behaviors that are frequently or seldom performed in the clinical field are identified, encouraged, and fortified, thereby encouraging supportive behaviors such as relationships and communication with patients and family members, emotional support and cooperation among medical staff, and provision of adequate work environment from the department, and when steps are taken to more actively implement the process of nurses directly explaining advance directives to patients and family members and counseling them sufficiently when providing end-of-life care, the end-of-life care competency of nurses will improve and high quality end-of-life care can be provided.

Although this study is meaningful in that it examined endof-life care competency among nurses at tertiary hospitals and their associations with various factors, it has some limitations. First, since the research on factors that influence end-of-life care competency among nurses in South Korea is not sufficient, additional studies at hospitals of various sizes and in different regions are necessary. Education on advance directives according to the 2018 Act on Decisions on Life-Sustaining Treatment is necessary. Second, since the reliability of the tool that measured attitudes about advance directives was low in this study, it is recommended that future studies use a revised tool according to the updates of the 2018 Act on Decisions 
on Life-Sustaining Treatment. Third, the variance explained by the factors that influence end-of-life care competency in this study was not at a satisfactory level. In order to improve the proportion of variance explained, another study with an expanded list of factors that influence end-of-life care competency is warranted.

\section{CONFLICT OF INTEREST}

No potential conflict of interest relevant to this article was reported.

\section{ORCID}

Da-In Jeong, https://orcid.org/0000-0003-0703-082X
Young Eun, https://orcid.org/0000-0002-3497-8192

\section{AUTHOR'S CONTRIBUTIONS}

Conceptualization: DIJ, YE. Data curation: DIJ. Formal analysis: DIJ, YE. Funding acquisition: None. Investigation: DIJ. Methodology: DIJ, YE. Project administration: DIJ, YE. Resources: DIJ, YE. Software: DIJ, YE. Supervision: YE. Validation: DIJ. Visualization: DIJ. Writing - original draft: DIJ. Writing - review \& editing: DIJ, YE.

\section{SUPPLEMENTARY MATERIALS}

Supplementary materials can be found via https://doi. org/10.14475/kjhpc.2020.23.3.139.

\section{REFERENCES}

1. Provisional results of birth and death statistics 2018 [Internet]. Daejeon: Statistics Korea; 2018 [cited 2019 Feb 27]. Available from: http:// kostat.go.kr/wnsearch/search.jsp.

2. Go YS. Current status of end-of-life care in Korean hospitals. J Korean Med Assoc 2012;55:1171-7.

3. Choi SH. Nurses' joys and sorrows of caring for dying patients [master's thesis]. Seoul: Kyung Hee Univ.; 2011. Korean.

4. Ha YR. The knowledge and attitudes toward Advance Directives of cancer patients and main care givers [master's thesis]. Seoul: Yonsei Univ.; 2016. Korean.

5. Kelly A. The concept of the specialist community nurse. J Adv Nurs 1996;24:42-52.

6. Campbell B, Mackay G. Continuing competence: An Ontario nursing regulatory program that supports nurses and employers. Nurs Adm Q 2001;25:22-30.

7. Royal College of Nursing. A framework for nurses working in specialist palliative care : competencies project. London:RCN;2002.

8. Montagnini M, Smith H, Balistrieri T. Assessment of self-perceived end-of-life care competencies of intensive care unit providers. J Palliat Med 2012;15:29-36.

9. Kang J, Kim, Y, Yoo YS, Choi JY, Koh SJ, Joh HJ, et al. Developing competencies for multidisciplinary hospice and palliative care professionals in Korea. Support Care Cancer 2013;21:2707-17.

10. Lee HJ. Critical care nurses' perceived end of life care competencies and supportive behaviors and barriers [master's thesis]. Seoul: Seoul National Univ.; 2015. Korean.

11. Jeong YH. End of life care competencies and terminal care stress of nurses in long term care hospitals [master's thesis]. Asan: Soonchunhyang Univ.; 2018. Korean.

12. Lee GR. Factors influencing nurses' end-of-life care competency and performance [master's thesis]. Seoul: Korea Univ.; 2019. Korean.

13. Lee SM. End of life care competency and frequency of intensive care unit nurses [master's thesis]. Seoul: Seoul National Univ.; 2019. Korean.

14. Act on decisions on life-sustaining treatment for patients in hospice and palliative care or at the end of life 2017 [Internet]. Sejong: National Law Information Center; 2017 [cited 2017 Aug 04]. Available from: http://www.law.go.kr/LSW/eng/engLsSc.do.

15. Um GY. Nurses' experiences and educational needs regarding advance directives writing [master's thesis]. Seoul: Korea Univ.; 2015. Korean.

16. Koh CK. Advance directives and the roles of advanced practice nurses. Korean J Crit Care Nurs 2010;3:91-9.

17. Cheon HJ. Nurses' perception of good death and attitude toward advance directives [master's thesis]. Busan: Pusan Catholic Univ.; 2018. Korean.

18. Yoon YA. Clinical nurses' perception of death and end of life care stress [master's thesis]. Daegu: Kyungpook National Univ.; 2010. Korean.

19. Heo KS. Clinical nurses' perceived or experienced obstacles and supportive behaviors in providing care for terminally ill cancer patients 
[master's thesis]. Choongju: Konkuk Univ.; 2015. Korean.

20. Nelson JE, Angus DC, Weissfeld LA, Puntillo KA, Danis M, David D, et al. End-of-life care for the critically ill: A national intensive care unit survey. Crit Care Med 2006;34:2547-53.

21. Beckstrand RL, Kirchhoff KT. Providing end-of- life care to patient: critical care nurses' perceived obstacles and supportive behaviors. Am J Crit Care 2005;14:395-403.

22. Hong SW, Kim SM. Knowledge regarding Advance directives among community-dwelling elderly. J Korean Acad Soc Nurs Educ 2013;19:330-40.

23. Seo SY. The knowledge and attitude about the advance directives: focused on the home-based cancer patients registered in community health centers [master's thesis]. Busan: Catholice Univ. of Pusan.; 2019. Korean.

24. Kim MY, Kim KS. Korean nurses' attitude towards advance directives and end of life decision making. Korean J Crit Care Nurs 2010;3:77-90.

25. Jezewski MA, Brown J, Yow-Wu BW, Meeker MA, Feng J, Bu X Oncology nurses' knowledge, attitudes, and experiences regarding advance directives. Oncol Nurs Forum 2005;32:319-27.

26. Schwartz CE, Mazor K, Rogers J, Ma Y, Reed G. Validation of a new measure of concept of a good death. J Palliat Med 2003;6:575-84.

27. Jeong HS. Recognition towards good death among physicians and nurses in an area [master's thesis]. Busan: Catholic Univ of Pusan.; 2010. Korean.

28. Cho KM. Analysis of hospice care needs of patients with terminal lung cancer and their families [master's thesis]. Seoul. Yonsei Univ.; 2006. Korean.

29. Crozier F. Hancock LE. Pediatric palliative care: beyond the end of life. Pediatr Nurs 2012;38:198-203, 227; quiz 204.

30. Crump SK. Schaffer MA. Schulte E. Critical care nurses' perceptions of obstacles, supports, and knowledge needed in providing quality endof-life care. Dimens Crit Care Nurs 2010;29:297-306. 